\title{
An Infinitist Account of Doxastic Justification
}

\author{
Forthcoming in dialectica \\ John Turri \\ Huron University College \\ john.turri@gmail.com
}

\begin{abstract}
Any satisfactory epistemology must account for the distinction between propositional and doxastic justification. Can infinitism account for it? Proposals to date have been unsatisfactory. This paper advances a new infinitist account of the distinction. The discussion proceeds as follows. Section 1 sets the stage. Section 2 presents Peter Klein's account. Section 3 raises a problem for Klein's account and suggests an improvement. Section 4 raises a further challenge. Sections $5-7$ consider several unsuccessful attempts to meet the challenge. Section 8 presents my new proposal, which can meet the challenge. Section 9 concludes the discussion.
\end{abstract}

\section{Preliminaries}

Epistemologists standardly distinguish propositional from doxastic justification. Some proposition might be justified for your even though you don't actually believe it, or believe it for the wrong reas- 
ons, or believe it for the right reasons but in the wrong way. Call this type of justification propositional justification. It attaches to propositions relative to individuals. Doxastic justification attaches to concrete belief states (and doxastic states more generally). For your belief that $\mathrm{Q}$ to be doxastically justified, $\mathrm{Q}$ must not only be justified for you, but you must believe $\mathrm{Q}$ for the right reasons and in the right way. Knowledge requires doxastic, not merely propositional, justification. ${ }^{1}$

An adequate theory of justification must account for this distinction. Can infinitists account for it?

Infinitism has been around since at least Aristotle's time. But compared to its main non-skeptical competitors, foundationalism and coherentism, its resources remain largely underdeveloped and its potential benefits unappreciated. Through a series of papers over the last decade, Peter Klein has done more than anybody to revive infinitism's fortunes, thrusting it back onto the philosophical scene (e.g. Klein 1999; Klein 2005a; Klein 2007a). ${ }^{2}$ So let's begin with his account of the distinction.

\section{Klein's Account}

We can encapsulate Klein's account as follows. Here and throughout, understand each reason to be unique, so that no two Rs with distinct subscripts are identical.

See Turri (forthcoming) for further discussion.

2 Fantl 2003 gives an importantly different argument for infinitism. 
Infinitist propositional justification (IPJ): The proposition $\mathrm{Q}$ is propositionally justified for you just in case there is available to you at least one infinite non-repeating series of propositions (or reasons) such that $R_{1}$ is a good (and undefeated) reason to believe $Q$, $R_{2}$ is a good (and undefeated) reason to believe $R_{1}, R_{3}$ is a good (and undefeated) reason to believe $R_{2}, \ldots$, $R_{m+1}$ is a good (and undefeated) reason to believe $R_{m}$, for any arbitrarily high $\mathrm{m}$. (Klein 2005a, 135 - 6; Klein 2007a: 8, 11; compare Klein 2005b: 166)

Infinitist doxastic justification (IDJ): Your belief that $\mathrm{Q}$ is doxastically justified just in case $\mathrm{Q}$ is propositionally justified for you, and you have provided enough reasons along at least one of the infinite non-repeating series of reasons, in virtue of which $\mathrm{Q}$ is propositionally justified for you, to satisfy the contextually determined standards. ${ }^{3}$

A few more words about Klein's positive view are in order. First, knowledge requires doxastic justification (Klein 2007b, 158). This is

3 Says Klein $(2007 a, 10)$ : "The infinitist will take the belief that $\mathrm{p}$ to be doxastically justified for $S$ just in case $S$ has engaged in providing 'enough' reasons along an endless path of reasons." Notice that Klein says providing the reasons is both necessary and sufficient for doxastic justification. In response to Bergmann (2007), Klein (2007b, 26) indicates he might be willing to add that doxastic justification requires S's belief to be "based on" the justifying reasons. But he also suggests that basing is tantamount to there being "an available reason" that you "cite ... as a reason" for your belief, so it remains unclear how this potential revision affects his theory. 
uncontroversial. Second, doxastic justification requires you to actually go through the process of justifying your belief. It must be earned, much as an income or honest reputation is earned-at least for most of us (Klein 2005b, 158, 163, 170). This is controversial but I will not question it here (see Leite 2004 for discussion). Third, contextual standards determine what is admissible as a "bedrock" reason-a reason that, once you reach it, you are permitted to stop (Klein 2007a, 10 - 12; Klein 2005b, $170-1$ ). Crucially for the infinitist, it is always possible to properly challenge ad infinitum the contextual standards and thereby the erstwhile bedrock reason, although this never actually happens. Contextualism is very controversial, but I will not question it here because I want to see whether Klein's view granted in its entirety can adequately account for the distinction between propositional and doxastic justification.

\section{An Improvement}

I will now suggest an improvement to IDJ. My motivation is not that we can dream up fanciful counterexamples-as though that would be surprising. Rather, IDJ seems to omit something fundamentally important.

Meet Samira. Samira knows that Q. Under our assumptions it follows that Samira's belief is doxastically justified, so Samira has produced enough reasons along at least one infinite non-repeating series to satisfy the contextually determined standards. For simplicity suppose that $Q$ is propositionally justified for Samira in virtue 
of only one infinite non-repeating series of reasons, and for convenience call this series ' $Z$ '. (Nothing that follows depends essentially on this assumption; it merely simplifies greatly my presentation.) Again for simplicity suppose further that the contextually determined standards require Samira to produce the first three reasons along $\mathrm{Z}$ (again, nothing depends essentially on this assumption), which are:

$$
\mathrm{R}_{1}, \mathrm{R}_{2}, \mathrm{R}_{3} \text {. }
$$

So Samira has articulated the following justificatory structure:

$$
\mathrm{R}_{3} \rightarrow \mathrm{R}_{2} \rightarrow \mathrm{R}_{1} \rightarrow \mathrm{Q} .
$$

The arrow represents the 'is a reason offered in favor of relation.

But here an issue arises. Given that Samira has produced $R_{1}, R_{2}$, and $R_{3}, Z$ is not the only possible path she might be on, because $Z$ is not the only path beginning with $\mathrm{R}_{1}, \mathrm{R}_{2}, \mathrm{R}_{3}$. An infinite number of such paths exist. For Samira's belief to be doxastically justified, it is not enough for her to be on just any path beginning that way. If she were, it would be pure luck that she produced the correct path's first three steps. This sort of luck is perfectly compatible with propositional justification, but obviously not with doxastic justification.

We could put the point this way. Simply producing $R_{1}, R_{2}, R_{3}$ is insufficient. Samira could accomplish that by lucky random guessing. She must properly produce the reasons. ${ }^{4}$ Accordingly we

4 Klein $(2007,6)$ might have this in mind when he says that doxastic justification requires believing in "an epistemically responsible manner." He doesn't specify what believing responsibly requires. My subsequent discussion can be read as an examination of what form an 
should amend IDJ.

(IDJ*): Your belief that Q is doxastically justified just in case $\mathrm{Q}$ is propositionally justified for you, and you have properly provided enough reasons along at least one of the infinite non-repeating series of reasons, in virtue of which $\mathrm{Q}$ is propositionally justified for you, to satisfy the contextually determined standards.

So is Samira on the right path? Of course she is. By hypothesis she knows Q. And she would know Q only if she were on the right path.

\section{A Question}

But a further question arises. In virtue of what is Samira on the right path? Why is she on $\mathrm{Z}$ rather than, say, defective path $\mathrm{A}$, whose first three steps are also $R_{1}, R_{2}, R_{3}$ ?

$$
\begin{aligned}
& Z: R_{1}, R_{2}, R_{3}, R_{4 Z}, R_{5 Z} \ldots \\
& A: R_{1}, R_{2}, R_{3}, R_{4 A}, R_{5 A} \ldots
\end{aligned}
$$

For the infinitist's account to succeed, there of course must be a fact of the matter whether Samira is on Z, given that she knows Q. For if there is no fact of the matter whether she is on $\mathrm{Z}$, then it is not true that she is on $\mathrm{Z}$, whence it is not true that her belief is doxastically justified, whence it is not true that she knows Q. ${ }^{5}$

infinitist account of this concept might take.

5 Philipp Keller questioned whether the reasoning here was careful 
The next three sections consider some proposals for answering our latest question.

\section{Counterfactuals}

5.1 .

A tempting initial response is to go counterfactual: Samira is on $\mathrm{Z}$ because having reached $R_{3}$, if she were to consider the question 'Why accept that?', then she would offer $R_{4 Z}$ rather than $R_{4 A}$.

But this does not solve the underlying problem. For there is also:

$$
A^{*}: R_{1}, R_{2}, R_{3}, R_{4 Z}, R_{5 A} \ldots
$$

No matter the number of steps Samira takes, there will always be an infinite number of defective paths that share with $\mathrm{Z}$ those steps, but then veer off into an epistemic dead-end.

enough. More fully spelled out, here is why there must be a fact of the matter, given that Samira knows $Q$ :

1. Samira knows that $Q$ only if her belief is doxastically justified. (Premise)

2. Samira's belief is doxastically justified only if she is on path $Z$. (Premise)

3. She is on path $Z$ only if it is true that she is on path $Z$. (Premise)

4. It is true that she is on path $Z$ only if there is a fact of the matter whether she is on path Z. (Premise)

5. Therefore she knows that $Q$ only if there is a fact of the matter whether she is on path Z. (From 1 - 4, Hypothetical Syllogism) 
5.2 .

Consider next this proposal. Samira is on $\mathrm{Z}$ because for any step, $\mathrm{Rn}_{\mathrm{Z}}$, along $\mathrm{Z}$, if Samira were to reach $\mathrm{Rn}_{\mathrm{Z}}$ and consider the question 'Why accept that?', then she would offer $\mathrm{Rn}_{\mathrm{Z+1}}$.

Any proposal featuring counterfactuals faces tricky counterexamples. Imagine a case where we stipulate: if Samira were to reach $\mathrm{R}_{40 \mathrm{Z}}$ and was asked 'Why accept that?', then some powerful agency would intervene and prevent her from providing $\mathrm{R}_{41 \mathrm{Z}}$. Or maybe at some point Samira would have a nervous breakdown or get bored and just stop offering further reasons. Indeed Samira is guaranteed to fall short of articulating the entire series because by stipulation: she is mortal, the number of steps in $\mathrm{Z}$ is infinite, providing each reason takes some time, and super-tasking is not an option. ${ }^{6}$ Such problems surely merit attention. But I think a more alarming problem suggests itself, one that cannot be dismissed as a mere trick.

To illustrate this deeper worry, it will be convenient to stipulate that $\mathrm{Q}$ is the proposition Samira would express by saying 'I will never justify a belief beyond the $100^{\text {th }}$ step'. Surely any normal human could know this about him or herself. (If you're doubtful, please adjust the example by increasing it to whatever finite number step you wish.) At some point along the way-say, the $1, \mathbf{O o o}^{\text {th }}$ step-Samira would have acquired such overwhelming evidence that $\mathrm{Q}$ is false, that she would simply stop producing further reasons in favor of $\mathrm{Q}$

6 It is not an option for us humans as we are actually constituted, which is enough for my purposes. I concede that there are possible beings for whom super-tasking is an option. 
because she would have stopped believing $\mathrm{Q}$.

This case is more alarming than your average tricky counterexample to a counterfactual analysis. It is more alarming because Samira would rightly stop providing further reasons. She would have acquired conclusive evidence that the belief she is ultimately defending is, in the counterfactual situation, false.

The example is not an isolated fluke. We could plug in different clauses for ' $Q$ ' and create the same problem. The truth-value of the proposition need only be sensitive to some threshold-be it the passage of time or a limit on the repetitions of some performance-that the subject would flagrantly violate if he continued indefinitely providing reasons.

For example consider the proposition I would express by saying 'I will not live past my $\mathbf{2 0 0}^{\text {th }}$ birthday'. Surely I know that. Yet since offering each reason takes at least some time, and super-tasking is not an option, and any justifying series contains infinite steps, at some point I would stop offering further reasons because I would recognize that I was older than 200 years. And even if I did continue offering reasons, at some point it would become irrational because I would obviously be older than 200. Imagine me at my $201^{\text {st }}$ birthday party, still justifying my belief that I will not live past my $200^{\text {th }}$ birthday, even as I complain about how difficult it is to blow out all 201 candles and reminisce about how lucky I am to have reached the ripe old age of 201 ! 
5.3.

Consider this variant of the counterfactual proposal. Samira is on $\mathrm{Z}$ because for any step, $\mathrm{Rn}_{\mathrm{Z}}$, along $\mathrm{Z}$, if she were to reach $\mathrm{Rn}_{\mathrm{Z}}$ and consider the question 'Why accept that?' and offer a reason in response, then she would offer $\mathrm{Rn}_{\mathrm{Z}+1} .^{7}$

This proposal suffers the same fate. At some point it would be irrational for Samira to offer any further reason in the service of justifying the obviously false target belief that Q. For it would be painfully obvious to her that she long, long ago transcended the 100-step threshold, many times over. And surely it would be surprising if a patently irrational counterfactual performance could generate knowledge or doxastic justification.

\section{4}

Consider one final revision of the counterfactual strategy. Samira is on $\mathrm{Z}$ because for any step, $\mathrm{Rn}_{\mathrm{Z}}$, along $\mathrm{Z}$, if she were to reach $\mathrm{Rn}_{\mathrm{Z}}$ and consider the question 'Why accept that?' and appropriately offer a reason in response, then she would offer $\mathrm{Rn}_{\mathrm{Z+1}}$.

Notice two things about this proposal. First, it is puzzling because it is difficult to imagine appropriately offering the $1, \mathbf{O o O}^{\text {th }}$, $10,000^{\text {th }}$ or $100,000,000,000^{\text {th }}$ reason to support the claim that you will never surpass the 100-step threshold. Samira would somehow have to be deprived of virtually all the relevant evidence she had

7 Peter Klein suggested this possibility in conversation. I do not know if he positively endorses it. 
gathered. And it would be surprising if what Samira would do if deprived of nearly all the relevant evidence somehow doxastically justified her actual belief. Second, the revision is potentially trivial. In a straightforward sense it would be inappropriate to offer any reason other than the correct next one in the series. For this proposal to convince, then, the relevant sense of appropriateness would have to be explained.

\section{Multiple Paths}

Infinitists might jettison the misbegotten counterfactual strategy and instead respond as follows.

Return to the point where the problem originally seemed to arise. We observed that Samira's producing $R_{1}, R_{2}, R_{3}$ is consistent with her being on either $\mathrm{Z}$ or A. We stipulated that she knows $\mathrm{Q}$, which requires her to be on $\mathrm{Z}$, which in turn motivated us to ask what makes it the case that she is on $\mathrm{Z}$ rather than $\mathrm{A}$. But this overlooks an important possibility: perhaps she is on both paths! And as long as she is on Z-regardless of whether she is also on A-her belief is doxastically justified. Simply producing those three reasons makes it the case that she is on both paths and so explains why her belief is doxastically justified. ${ }^{8}$

Grant that simply producing those three reasons makes it the case that she is on both paths. The proposal is still inadequate. Simply being on $\mathrm{Z}$ in the way envisioned does not suffice for doxast-

8 Thanks to an anonymous referee for suggesting this. 
ic justification. It fails to rule out even the most egregious form of epistemic luck: randomly guessing $R_{1}, R_{2}, R_{3}$ would suffice! The imagined response essentially reverts back to IDJ, ignoring the lesson that drove us to adopt IDJ*. This type of luck is perfectly consistent with propositional justification-guessing does not deprive you of the reasons or stop them from propositionally justifying $Q$ for you. But guessing obviously does not suffice for doxastic justification. Samira must not only be on the right path. She must be on the right path in the right way.

Abandoning the "path" metaphor, the point is that she must properly produce the relevant reasons. The present proposal offers no insight into that important status, crucial to the distinction between propositional and doxastic justification.

\section{Tu Quoque?}

But is the infinitist being unfairly singled out for criticism here?9 Does anyone have a satisfactory account of doxastic justification? You might suspect that infinitist and finitist alike face the same problem, in which case we have located no special problem for infinitism.

My response is twofold. First, if the suspicion is correct, then the present discussion reveals an urgent problem facing all theories of justification, considerably enhancing its importance. In a certain sense, that would please me. Nevertheless, second, the suspicion is

9 Thanks to an anonymous referee for raising this question. 
not correct. Infinitism's competitors face no such problem in principle.

To substantiate this last point, consider a simple foundationalist view, what I'll call simple empiricism. (I don't here endorse simple empiricism, but rather deploy it to conveniently illustrate a point.) Simple empiricism says (i) $Q$ is propositionally justified for you just in case you have an experience that Q; (ii) your belief that $\mathrm{Q}$ is doxastically justified just in case it is properly based on an experience that Q; and (iii) your belief that $Q$ is properly based on an experience that $\mathrm{Q}$ just in case the experience's causing your belief manifests your cognitive disposition to take experience at face value. ${ }^{10}$ Now suppose Samira has an experience that $\mathrm{Q}$. This renders Q propositionally justified for her. She knows Q, so her belief must be doxastically justified, so she must be on the right path in the right way. According to simple empiricism, in virtue of what is she on the right path in the right way? In virtue of the fact that her experience's causing her belief manifests her reliable cognitive disposition to take experience at face value.

Without ruining the basic point, the simple empiricist may add that for your belief to be properly based on the experience, you must also cite the experience or verbally express your acceptance of the experience as a good reason to accept Q. This is in keeping with Klein's view that you must do something to earn doxastic justification.

\footnotetext{
${ }^{10}$ Turri (unpublished $\mathrm{ms}$ a) defends a related account of the epistemic basing relation.
} 
Consider also simple coherentism. (Again I do not here endorse simple coherentism.) Simple coherentism says that (i) $Q$ is propositionally justified for you just in case Q coheres with (some proper subset of) your beliefs $B_{1} \ldots$ Bn, where $n$ is finite; (ii) your belief that $\mathrm{Q}$ is doxastically justified just in case it is properly based on $B_{1} \ldots B n$; and (iii) your belief that $Q$ is properly based on $B_{1} \ldots$ Bn just in case $B_{1} \ldots$ Bn cause you to believe $Q$ through a manifestation of your cognitive disposition toward coherence. Now suppose that Samira holds beliefs $B_{1} \ldots$ Bn. This renders Q propositionally justified for her. She knows Q, so her belief must be doxastically justified, so she must be on the right path in the right way. According to simple coherentism, in virtue of what is she on the right path in the right way? In virtue of the fact that her beliefs $B_{1} \ldots$ Bn caused her to believe $\mathrm{Q}$ through a manifestation of her cognitive disposition toward coherence. ${ }^{11}$

Again without ruining the basic point, we may add that for your belief to be properly based on the other beliefs, you must also cite them or verbally express your acceptance of them as a good reason to accept Q.

\section{Mimicry}

Perhaps the infinitist can say Samira's belief is doxastically justified

11 An anonymous referee questioned whether the challenge I pose for infinitism stems from the fact that infinitism disallows non-beliefs to play the role of reasons. The discussion of simple coherentism puts this worry to rest because it disallows non-beliefs to play that role. 
in virtue of the fact that her production of $R_{1}, R_{2}, R_{3}$ manifests her relevant cognitive dispositions.

The main task facing this proposal is to identify the relevant dispositions. We know what it is to be disposed to take experience at face value-we do it all the time. We know what it is to trust coherence-we do that every time we accept some conclusion because it "fits" with what we already believe. What dispositions will the infinitist invoke?

But this task isn't so difficult after all. The infinitist can help himself to whatever dispositions his opponents help themselves to. ${ }^{12}$ Or he might "go contextualist" about the relevant dispositions: along with contextual standards determining what is admissible as a bedrock reason, contextual standards also determine what counts as an admissible cognitive disposition. Either way, a penchant to just guess will almost certainly not show up on the list of relevant dispositions.

\section{Conclusion}

Where does this leave us? We asked, In virtue of what is Samira on the right path in the right way?, or less metaphorically, In virtue of what has Samira properly produced the relevant reasons? The infinitist can respond: in virtue of the fact that Samira's production of

12 Klein $(2005 a, 136-7)$ makes a parallel suggestion regarding an infinitist account of what makes something a (good) reason for you to begin with. 
$R_{1}, R_{2}, R_{3}$ actually manifests her relevant cognitive dispositions, whatever those dispositions may be.

This proposal is not ad hoc. It does not violate infinitism's other commitments. Invoking the manifestation of cognitive traits is equally available to foundationalist, coherentist and infinitist alike. At the very least, the infinitist appears to have just as plausible a story to tell as her competitors. True, we might want a more complete story about what the manifestation of dispositions requires. But infinitism suffers no relative disadvantage as a result. And it is something we would have wanted in any case because the manifestation of dispositions is pervasive throughout the physical and social world.

I conclude that we have identified a plausible infinitist account of doxastic justification, including what distinguishes it from propositional justification. Of course this does not answer all questions about infinitism. There remain serious questions about the main positive arguments for infinitism. ${ }^{13}$ There also remain questions about the contextualist element of IDJ* ${ }^{*}$ But those are issues for another day. For now infinitists can take heart in our present results. ${ }^{14}$

${ }^{13}$ For discussion of Klein's "regress argument" see Turri 2009; for discussion of Fantl's "features argument" see Turri (unpublished ms b).

${ }^{14}$ For superb feedback that helped improve this paper, I thank the editors of this journal (along with any anonymous referees who helped them in the process). Special thanks also to Peter Klein for helpful discussion early on. 
References

Bergmann, M. 2007, "Is Klein an Infinitist about Doxastic Justification?" Philosophical Studies 134, 19 - 24.

Fantl, J. 2003. "Modest Infinitism", Canadian Journal of Philosophy 33, $537-562$.

Klein, P. 1999, "Human Knowledge and the Infinite Regress of Reasons", Philosophical Perspectives 13, $297-325$.

Klein, P. 2004, "What IS Wrong with Foundationalism is that It Cannot Solve the Epistemic Regress Problem", Philosophy and Phenomenological Research 68, $166-171$.

Klein, P. 2005a, "Infinitism Is the Solution to the Regress Problem", in: M. Steup and E. Sosa, eds, Contemporary Debates in Epistemology, Malden, MA: Blackwell.

Klein, P. 2005b, "Infinitism's Take on Justification, Knowledge, Certainty, and Skepticism", Veritas 50, 153 - 72.

Klein, P. 2007a, "Human Knowledge and the Infinite Progress of Reasoning", Philosophical Studies 134, 1- 17.

Klein, P. 2007b, "How to Be an Infinitist about Doxastic Justification", Philosophical Studies 134, 25 - 29.

Leite, A. 2004, "On Justifying and Being Justified", Philosophical Issues 14, Epistemology, 2004.

Turri, J. 2009, "On the Regress Argument for Infinitism," Synthese $166,157-163$.

Turri, J. Forthcoming, "On the Relationship Between Propositional and Doxastic Justification", Philosophy and Phenomenological Research.

Turri, J. Unpublished ms a, "Believing for a Reason".

Turri, J. Unpublished ms b, "Foundationalism for Modest Infinitists". 